\title{
ARTICLE
}

\section{Internet sex addiction: a licence to lust? ${ }^{\dagger}$}

\author{
Nick Dunn, Matthew Seaburne-May \& Philip Gatter
}

\begin{abstract}
Nick Dunn is a consultant adult general psychiatrist for Surrey and Borders Partnership NHS Foundation Trust. From 1996 to 2008 he worked in the Sex and Relationship Problems Clinic at Guy's Hospital, London. Matthew Seaburne-May is a community consultant adult genera psychiatrist with the South London and Maudsley NHS Foundation Trust. He has a specialist interest in adult attention-deficit hyperactivity disorder (ADHD). Philip Gatter completed a doctorate in social anthropology and subsequently worked for 12 years as a Senior Research Fellow at London Southbank University, with a primary research interest in sexual health and HIV/AIDS. Since 2003 he has been Research and Academic

Co-ordinator for the South London and Maudsley NHS Foundation

Trust, and Honorary Senior Research Fellow at the Institute of Psychiatry. $\mathrm{He}$ is a qualified psychotherapist, and has a clinical and research interest in psychosexual problems. Correspondence Dr Nick Dunn, Redhill Reigate Horley Community Mental Health Recovery Service, Shaws Corner, Blackborough Road, Reigate RH2 7DG, UK. Email:
\end{abstract} nicholas.dunn@sabp.nhs.uk

${ }^{\dagger}$ For a companion article on shopping addiction and a related commentary see pp. 263-269 and 278-279, this issue.

\begin{abstract}
SUMMARY
In this article we ask what kind of phenomenon is internet sex addiction. From the perspectives of two practising psychiatrists, one of whom has worked in a weekly sexual disorders clinic for 12 years, and an anthropologist we explore whether a moral panic is emerging over sexual behaviour and the internet, and whether internet sex addiction forms part of any such panic. We ask whether many individuals who diagnose themselves as addicted to internet-based sex do so more out of a media-activated sensibility than a clinical reality. We also consider what developments in DSM-5 hold for this area.
\end{abstract}

\section{DECLARATION OF INTEREST}

None.

'The expense of spirit in a waste of shame Is lust in action: and till action, lust Is perjured, murderous, bloody, full of blame, Savage, extreme, rude, cruel, not to trust; Enjoyed no sooner but despised straight; Past reason hunted; and no sooner had, Past reason hated, as a swallowed bait, On purpose laid to make the taker mad. Mad in pursuit and in possession so; Had, having, and in quest to have extreme; A bliss in proof, and proved, a very woe; Before, a joy proposed; behind a dream. All this the world well knows; yet none knows well To shun the heaven that leads men to this hell.'

(William Shakespeare, Sonnet 129)

The internet does not have an easily identified 'first day', as it was created over time via the amalgamation of various networks. However, until 1989, when the first 'internet service provider' (ISP) was formed, it was a research-institute only tool, for data in text and number form. Despite this, GriffinShelley (2003) reports that articles on sex and the internet appear as early as 1983. The internet has revolutionised communication, shopping and education, generally in a socially acceptable way. Yet it has also made pornography freely accessible and facilitates off-line sexual liaisons between strangers. This aspect of the internet has polarised the debate about its benefits and risks.

Internet sex addiction, or cybersex addiction, describes internet-based sexual activities that are deemed excessive. Reported problems in this area include people who have damaged their primary relationships through searching internet porn (Young 2000). Some have spent excessively and lost employment because of a sexual preoccupation mediated by the internet (Carnes 2010). The problem that these people have has been variously characterised as an addiction, an obsessional phenomenon and a compulsion. It is one of many subjectively compulsive behaviours that is attracting interest as a future area for developments in conceptualising mental disorders. This article seeks to explore the meaning of internet sex addiction in popular culture and in scientific discourse.

\section{What does internet sex addiction mean?}

A number of behaviours are encompassed by the term internet sex addiction. It is used variously (e.g. Griffiths 2000) to describe excessive use of the internet, for example:

- to seek out material for masturbatory use online

- to meet others for sexual congress, either for mutual gain or for payment

- to buy sexually explicit material/sexually related goods that can be used offline.

All of these behaviours can be pursued without the help of the internet. There is therefore a grey area between 'standard' sex addiction and internet sex addiction. However, the internet has provided entirely new forms of sexual activity, and it has made some existing forms much more widely available, affordable and anonymous, increasing their attractiveness to some people.

\section{How important is the internet in sexuality?}

Pornography has long been a driver of technology. Wasko (1994) suggests that the defeat of Betamax video technology by the VHS format was driven by the greater availability of pornography in the latter. Coopersmith (1999), among others, describes how Minitel and camcorders benefited from being suitable for pornographic use, while on the internet, the development of streaming video and secure online payment was led by the pornography industry. Lajeunesse (2009) has suggested 
that, since the advent of freely available pornography on the internet, researchers struggle to find research participants who have not viewed it.

On 12 February 2012, Alexa (an online information company that lists the top 500 sites on the web) listed Google, Facebook and YouTube as the most popular sites visited. The highest-ranked adult websites were XVIDEOS.com at 53rd and xHamster.com at 55th (www.alexa.com/topsites).

Worry over internet sex behaviours has taken the form of several distinct discourses, which we will consider in turn.

\section{The media discourse}

'Nobody enjoys disease, but there is no doubt that some people enjoy sin. Hence it is easier to treat or prevent disease than to eliminate sin.'

Richard Asher (1984)

A Sense of Asher: A New Miscellany

Perhaps as a result of the behaviour of famous people such as Michael Douglas and Tiger Woods, sex addiction is now part of the public discourse (Henley 2010). The behaviour of the few is used by the media to imply that internet sex addiction is a serious and widespread problem damaging relationships. In contrast, the presentation of sex addiction in general psychiatry is uncommon. Of all modern technologies that can be used to access porn, including mobile phones and cable television, the internet has been singled out as an agent of addiction. The reason for this is unclear, although it may relate to usability and convenience.

The media reports that internet sex addiction is highly prevalent. On the BBC website, Dr Tricia Macnair (2010) states that $6 \%$ of the population are sex addicts and that 1 in 5 with the addiction are women. Sex addiction is considered analogous to chemical addiction; gurus are quoted and screening tests and stories of recovery reported. Medical legitimacy is sought, perhaps to reduce stigma and move the concept of sex addiction from something that one does to something one has, with associated disease notions of treatment and cure.

The internet is also cited in cases of litigation:

'At a 2003 meeting of the American Academy of Matrimonial Lawyers, two thirds of the 350 divorce lawyers who attended said the Internet played a significant role in the divorces in the past year, with excessive interest in online porn contributing to more than half such cases. Pornography had an almost non-existent role in divorce just seven or eight years ago' (Divorce Wizards 2011).

\section{The scientific discourse}

Goodman (1990) writes that all that is required to turn any behaviour into an addiction is powerlessness to control it, despite significant negative consequences. He makes a case for a biopsychological process that is shared by substance use disorders, bulimia nervosa, pathological gambling and sexual addiction (Goodman 2008).

The vast majority of published papers on internet sex addiction appear in journals specialising in the field, such as Cyberpsychology, Behavior, and Social Networking (USA) and Sexual Addiction $\&$ Compulsivity (UK). For comparison, all the journals published by the American Psychiatric Association contain only one case study on the subject (Bostwick 2008), and there have been no papers on it in any journal published by the Royal College of Psychiatrists.

Surveys of sexual behaviour are inherently difficult because of sample selection and bias in reporting (Wellings 1994). Kinsey's classic surveys interviewed only volunteers. Wellings et al's 1994 survey of sexual behaviour in Britain initially suffered political inference: the Thatcher government criticised its intrusiveness, cost and duplication of other studies, and it was saved only by the intervention of the Wellcome Trust (Durham 1989).

In the sympathetic literature, cogent and coherent arguments are made for the existence of internet sex addiction as an illness, on the basis of its long historical pedigree and of the subjective distress and socioeconomic restriction of sufferers. The majority of papers are descriptive studies based on clinicians' experiences in the field: few case or cohort studies or large-scale surveys have been published. An exploratory approach is typified by Delmonico \& Carnes (1999), who used case studies to investigate the area and offered a prototype screening test.

The papers in the specialised journals are polarised in favour of the existence of internet sex addiction as an illness, with Cooper (2000) going as far as to call any critique of this view "narrow and uninformed'. However, Cooper (1999) has also conducted one of the largest studies, in which over 9000 internet pornography users were surveyed. Heavy users (8\%) reported significant problems, typically associated with compulsive disorders.

\section{Recent surveys of internet use}

Overuse of pornography, infidelity and risky behaviours are the internet-related problems most frequently treated by mental health professionals (Mitchell 2005). Over half of all spending on the internet is estimated to be related to sex (Yoder 2005). Among 10- to 17-year-old internet users surveyed, $42 \%$ had been exposed to internet pornography in the past year; $66 \%$ of these exposures were reported as unwanted (Wolak 2007). 
A survey of sexual practices in Australia interviewed 10173 men and 9134 women aged 16-59 years (Richters 2003). Of these, $17 \%$ of the men and $2 \%$ of the women had intentionally visited an internet sex site. Among the men, positive associations were found with being gay or bisexual, younger than 50, of higher educational achievement, a city dweller and having no regular partner. Among the women, the associations were with younger age, being gay or bisexual and having more than one sexual partner. In a study of 270 young men who had sex with men, $48 \%$ had had sex with a partner they had met online; only $53 \%$ had consistently used condoms in these encounters (Garofalo 2007). Those who used the internet to meet sexual partners also engaged in other behaviours that placed them at risk of HIV and other infections.

\section{Feminist perspectives}

Feminist discourses have had a powerful but complex influence on societal evaluation of pornography, at least since the late period of second-wave feminism in the 1970s and early 1980s. Initially, this largely took the form of a radical anti-pornography position, typified by the work of Andrea Dworkin and Catherine MacKinnon (Dworkin 1979; MacKinnon 1984). The production of porn was seen as harmful and degrading to the women who participated in it, whether consenting or not. Its consumption was equally pernicious, since women were depicted as sex objects, frequently subject to violent sexual acts, distorting views of human sexuality, and encouraging misogyny and violence against women (Morgan 1974; MacKinnon 1987). Campaigning groups emerged in the UK at this time, including the Campaign Against Pornography and Women Against Violence Against Women.

Other strands of feminist thought emerged during the so-called 'Sex Wars' of the 1980s. These did not condone or encourage pornography, but they did criticise anti-porn feminists on the grounds of their sex-negativity and encouragement of censorship. The group Feminists Against Censorship was formed in the UK. Pro-sex, anticensorship feminists argued that, in context, pornography could be an acceptable part of sexual expression, so long as it did not involve exploitation (Willis 2005). Pornography was not in essence bad: indeed, it could provide a way in which women exerted their sexual agency. Going further, some feminists have labelled themselves pro-pornography and become involved in the making of pornography. There is now an annual Feminist Porn Awards in Toronto, which accepts submissions of films directed or produced by women, in which genuine female pleasure is depicted, and the sexual stereotypes found in mainstream porn are challenged. Nevertheless, the majority of feminists remain anti-porn: former UK Home Secretary Jacqui Smith (2011) has arrived at her own anti-porn view, following a scandal 2 years previously, when she mistakenly claimed parliamentary expenses for pay-per-view porn films watched by her husband.

\section{Moral panic}

\section{Legislative control}

Historians and social scientists have argued for some time that sex has been used as an instrument to police the boundaries of morality in society (Weeks 1985, 1986; Herdt 2009). Sex has always been seen as potentially dangerous. In Britain, the late 19th century saw the introduction of legislation which sought to control homosexuality and prostitution together, in pursuit of 'protecting' the bourgeois family from destructive forces. This thinking has not entirely gone away.

At the same time, sex was promoted as taking place appropriately only between a married man and woman in pursuit of procreation. No new law relating to homosexual practice had been introduced since Henry VIII's anti-sodomy statute of 1533 , which related to any non-procreative sex, regardless of the gender (or even species) of participants. Henry Labouchère's 1885 Amendment (Section 11 of the Criminal Law Amendment Act) introduced the offence of gross indecency into British law, an offence whose precise nature was not spelled out, but which in practice was used to prosecute male homosexual acts where sodomy could not be proved. Oscar Wilde was the most significant early victim of this legislation. The rest of the Criminal Law Amendment Act concerned itself with sexual assaults on young women and the control of prostitution.

\section{Public opprobrium}

Against this background of increasing legislative control, the late 19th century in Britain and elsewhere in Europe saw a stand-off between forces fighting for a liberalisation of attitudes towards sex and sexuality, such as sexologist Magnus Hirschfeld's Scientific Humanitarian Committee in Berlin, ranged against those in moral panic about sexual mores. One behaviour of great concern was masturbation.

From the 18th century, (male) masturbation had come to be seen as a dangerous form of sexual expression divorced from married fidelity. 
The idea that masturbation might lead to mental feebleness now strikes us as absurd, but compulsive masturbator, poet and (probably) homosexual Edward Lear is likely to have attributed his epilepsy to the 'solitary vice', according to at least one biographer (Mars-Jones 2001). The attribution of epilepsy as punishment for masturbation was another myth of the time.

We mention Edward Lear because he was clearly preoccupied with his habit, as his diary of 1887 shows (Lear 1887). Typically, he indulged in it seven times a day, it was aversive to him, and he led a somewhat barren intimate life. He craved companionship and reciprocated physical and spiritual love with a young man, but this was to elude him. Might we be tempted to label him retrospectively a sex addict, albeit without the internet?

\section{What is a moral panic?}

Moral panics were first defined in the seminal work of sociologist Stanley Cohen, whose 1972 publication Folk Devils and Moral Panics examined the popular reaction to the 'delinquent' youth culture of mods and rockers, associated in particular with violence in Brighton. His title refers back to such 'folk devils' as the unfortunate women prosecuted as witches in the 17th and earlier centuries. He argued that 'societies appear to be subject, every now and then, to periods of moral panic. A condition, episode, person or group of persons emerges to become defined as a threat to societal values and interests' (Cohen 1972: p. 9).

The concept of moral panic was later linked to sex and sexuality explicitly through analyses of 19thcentury moral crusades against homosexuality and prostitution (Weeks 1981; Rubin 1984). In recent history (Watney 1987), moral panics surrounding sex have emerged through HIV/ AIDS (which again demonised homosexual men), pro- and anti-pornography campaigns, further campaigns against prostitution but also those in favour of protecting the rights of sex workers: it is interesting in this connection that feminism has served both conservative and liberal impulses.

Sexual panics are a subspecies of moral panic (Herdt 2009). In a true sexual moral panic, people become:

'overwhelmed by and defined through the meanings and rhetoric of sexual threats and fears. [...] the sexual "folk devil" - the sexual other, whether oversexed or undersexed - is stripped of rights, and the cultural imagination becomes obsessed with anxieties about what this evil sexuality will do to warp society and future generations' (Herdt 2009: p. 5)

In the sexual scandals relating both to Oscar Wilde and former American President Bill
Clinton, what began as scandal ended in spectacle, and both these events belong to the class of moral panics.

\section{Child pornography: new folk devils}

Recently, an intersection has been recognised between use of the internet and sexually prohibited activity. This is perhaps most clear in the West in terms of the production and use of child pornography. The number of prosecutions continues to mount, surrounded by fears that predatory paedophiles may be our virtual as well as actual neighbours, hiding who they are by masquerading as others (typically adolescents) on the internet. It might be argued that a moral panic is occurring specifically regarding the nefarious use of the internet by networks of paedophiles.

Linked with this is the emergence of stories of police officers charged with investigating child pornography, who have become offenders themselves. On 10 October 2010, the BBC reported the exposure of an internet paedophile ring in Spain which included two police officers, among other public servants (BBC News Europe 2010). This fits with a constitutive fear in sex panics - that the 'folk devils' will somehow proselytise, infect or convert others into themselves - an old fear in relation to homosexuality, though a realistic one in terms of paedophiles using the internet to groom victims.

\section{Consenting adults?}

In March 2003, Jane Longhurst, a special needs teacher, was strangled to death. Her killer, Graham Coutts, failed to persuade a jury that she died accidentally during consensual erotic asphyxiation and was convicted of murder. A campaign led by her mother Liz Longhurst calling for a ban on websites depicting violence against women culminated in legislation making possession of extreme pornography illegal in the UK (Criminal Law Policy Unit 2009). Sadomasochism (S\&M or SM) groups argue that this is an overreaction criminalising people who consent to sexual activity (Champion 2010). Lord Wallace of Tankerness called the legislation flawed because it makes illegal the possession of an image of behaviour, which in itself would not be an offence (Hansard 2008).

But how is it possible to establish that the participants in extreme pornography are truly consenting? Children never 'consent' to working in the sex industry and there is an established link between victims of human trafficking and child pornography (Office of the United States High Commissioner for Human Rights 2000). We 
support the policing of the internet against the sexual abuse of children.

A moral panic requires more than a disproportionate reaction. There has to be consensus that there is a genuine threat to social values. There is no good evidence of a widespread belief that viewing images of consenting adults indulging in fantasy behaviour is damaging.

In the terms outlined above, it appears that there is no moral panic specifically about sex addiction and the internet, at least not yet. The sex addict as represented in the media by, for example, Tiger Woods, is likely to be seen as deserving of sympathy, pathetic or simply not believed: sex addiction is his excuse. The media has, however, played an important role in publicising sex addiction, starting with celebrities, and this may influence some people's self-labelling as sex addicts. In 1997, David Duchovny (star of The $X$ Files) was labelled a 'sex addict'. He denied the charge at the time, but in 2008 he admitted to several years of addiction (Serjeant 2008).

\section{A stand-alone disorder?}

The literature offers various conceptualisations of excessive nonparaphilic sexual disorder based on the models of obsessive-compulsive disorder, impulse control disorder, out-of-control excessive sexual disorder, and addictive disorder (Garcia 2010). However, studies suggest that, if internet sex addiction does exist, it is not a stand-alone disorder, but a behaviour arising in association with several other psychiatric disorders.

For example, a review by Krueger et al (2009) of 60 men convicted of child-related internet sex offences reported that $33 \%$ had diagnosable hypersexuality and 70\% had an Axis I disorder deemed to be contributory to their offending behaviour. Black et al's (1997) study of 36 people (28 men and 8 women) who responded to advertisements for people with 'a problem with compulsive sexual behaviour' found an association with substance misuse (64\%), anxiety disorders (50\%) and mood disorders (39\%). Cooper et al (1999) reported that, compared with controls, a group with self-identified sexual addiction commonly had dissociative experiences and a tendency to seek out sexual experiences when depressed or anxious.

\section{A definable or measurable disorder?}

Hypothesised dimensions of internet sex addiction have been crystallised into several different rating scales, for example the Sexual Addiction Screening Test (SAST; Carnes 1991). These have undergone little in the way of validation, but are accepted in some spheres as useful tools in making a diagnosis.

No clear criteria for when sexual interest becomes excessive have yet been robustly defined. Kafka's (1997) threshold of seven orgasms a week seems entirely arbitrary, and indeed other studies (e.g. Winters 2010) have suggested that a high proportion of the population would be hypersexual by this measure. There are also cultural norms to be considered, such as gay men having more sexual partners in the previous 5 years than the population average (Wellings 1994: p. 216). Proponents of internet sex addiction as a disorder resolve this problem by arguing that it is the degree of subjectively experienced distress that should be the overriding consideration. However, this gives rise to further problems. First, the definition rests on circular reasoning: internet sex addiction exists because people say they suffer from it. Second, the degree of suffering, the level of distress that justifies the diagnosis, can be varied depending on who is making the diagnosis and to what end.

\section{Towards the future}

\section{DSM-5}

The pathology of behaviour has been an area of considerable discussion in the formulation of the first draft of DSM-5, currently available only online, although referenced in various press releases (American Psychiatric Association 2010). It is proposed that problems people experience taking illicit drugs should be re-conceptualised as compulsive drug-seeking behaviour, rather than neurochemical addiction. This leaves the door open for many subjectively compulsive behaviours to be bracketed with more traditional addictions. Consequently, behaviours such as excessive gambling, shopping, computer game use, contact sexual behaviours and the use of internet pornography become seen as health problems. ${ }^{\ddagger}$

Gambling addiction is currently in DSM-5, albeit in a distinct section on impulse control disorders. Internet addiction was considered for inclusion there, but rejected. No mention was made of internet sex addiction (DSM-5 Task Force 2012a). The concept of excessive internet use as an addictive behaviour has previously been reviewed in this journal by Murali \& George (2007), who concluded that debate on the diagnostic validity of the concept was slowing progress in its delineation.

In the DSM-5 drafts (DSM-5 Task Force 2012b), gambling disorder is defined as a persistent and recurrent maladaptive behaviour as indicated by five (or more) of the following:

1 preoccupation with gambling (e.g., reliving past gambling experiences, planning the next 
venture, or thinking of ways to get money with which to gamble)

2 the need to gamble increasing amounts of money to achieve the desired excitement

3 repeated unsuccessful efforts to control, cut back, or stop gambling

4 restlessness or irritability when trying to cut down or stop gambling

5 using gambling as a way of escaping from problems or of relieving dysphoria (e.g., feelings of helplessness, guilt, anxiety, depression)

6 after losing money gambling, returning another day to get even

7 lying to conceal the extent of gambling

8 jeopardising or losing a significant relationship, job, or educational or career opportunity because of gambling

9 relying on others to provide money to relieve financial straits caused by gambling.

All of these criteria could have direct equivalents in internet sex addiction apart from criterion 6 . Much of the fear in the media regarding internet sex addiction arises from the equivalent of criterion 2 - an internet sex addict would have to seek out ever more extreme or bizarre forms of pornography to achieve the same release. It is easy to postulate that this might lead to progression from adult to child pornography. However, evidence that it does so is very thin on the ground.

\section{Psychiatry unlimited and the DSM-5 diagnosis}

Just as you can substitute the words internet pornography for the word gambling to generate a new disorder, so you can for a huge number of other words representing behaviours that are known to be taken to extremes. Golf is a good example. The concept of the 'golf widow' has long been in the lexicon. Keen golfers are known to be happy on the golf course (criterion 5), talk about little other than golf (criterion 1) and spend everincreasing time on it (criterion 3). Other criteria in the DSM-5 list might be similarly applied. Thus, DSM-5 might open up many areas of new 'illness'. In fact, it follows that there will be no pleasurable pastime that could not potentially attract a psychiatric diagnosis.

\section{Behaviours in context}

Therefore, before excessive interest in an activity or behaviour is declared an illness, effort must be taken to put it into a cultural and societal context. There are two elements to this. First, there is often (although not always) an inner drive. In internet sex, this is the libido. The fact that excessive internet sex is used to fulfil a sexual urge or drive that is an in-built human need will always make it seem more problematic than excessive behaviours for which there is no equivalent drive. Control of the excesses of human libido has been of great societal concern as far back as one cares to research, as outlined above.

Second, there is the status of the behaviour in the social context. Sexual behaviour has a unique position in society, and it is judged to a very different standard than other behaviours. The threshold at which sexual activity is seen as excessive, and consequently a problem, is largely culture bound. Societies tend to assess behaviour in terms of its goal direction, linked to social roles and values. Work attendance, home maintenance, worship and recreation are dependent on social learning, not the waxing and waning of an appetite. Sleep, sex, eating and drinking are appetite driven: they are reduced by satiation and are further behaviourally modified by social values and culture.

Excesses in sexual activity, as in gambling or similar behaviours, can be assessed using objective measures such as occupational impairment. However, society's reaction to excessive sexual activity is very different from its reaction to excessive gambling. Consequently, the standard approach of measuring distress in the subject and disquiet in their social network using instruments such as the Sexual Compulsivity Scale (Kalichman 1994) is likely to result in overdiagnosis of that excessive sexual activity.

As stated earlier, internet sex addiction is rarely encountered in the adult psychiatrist's daily NHS work. The rare presentations are usually highly dependent on the social context. Commonly, there is a crisis of disclosure: the individual's family or employer has discovered their use of the internet for sexual purposes. Reactions on being found out vary. Some present with shame and depressive attitudes, perhaps asking why they do it and requesting medication or a cure. Others wonder what is all the fuss is about, but must be seen to be going through the motions of treatment.

\section{Conclusions}

The differing perspectives outlined here lead to several possibilities as to the real state of internet sex addiction. It could be common or rare. Some estimates put the prevalence of all sex addiction at $8 \%$ (Barth 1987). It might be most frequently seen alone or comorbid with chemical dependence. It may be independent of societal fashion, or it may be related to a moral panic. Sex addiction (as distinct from internet sex addiction) was first coined as a term in 1977, the popular discourse pre-dating the scientific. It derived from the 


\section{MCQ answers}

$\begin{array}{lllll}1 \mathrm{e} & 2 \mathrm{~b} & 3 \mathrm{c} & 4 \mathrm{a} & 5 \mathrm{~d}\end{array}$
Alcoholics Anonymous twelve-step programme, which has its origins in 1935.

Is there a clear threshold for a disorder, or is the normal range for the human libido yet to be delineated or even plastic and undergoing a process of reshaping under internet forces?

Internet sex addiction is a concept that obscures more than it illuminates. The diagnostic definition of addiction is so broad that 'criteria creep' might include any pleasurable activity. This disparity between postulated and observed prevalence is an example of the medicalisation of everyday life (Moynihan 2010).

Applying the term addiction to internet sex has a social context. Infidelity and the use of pornography pre-dated the internet but the internet makes them easier. We believe that the construct of internet sex addiction currently lacks validity. Media interest in internet sex addiction oversimplifies the experience and management of those who present with problem internet use. Internet sex addiction is not a unitary behaviour and those lobbying for a unitary diagnosis run the risk of ignoring comorbid psychiatric disorders.

Clinicians need to be aware that perhaps half of men who have sex with other men find their sexual partners through the internet, and that around half of these do not practise safe sex. Clinicians will also see distressed patients and families worried about internet sex and seeking psychiatric assessment and advice.

New societal forces are shaping attitudes to sexual behaviour. Such influences include a more intrusive media, eager to exploit the selling power of sexual revelation, an addiction lobby that seeks medical legitimacy for various behaviours and a pharmaceuticals industry that asserts that, whether one's libido is too low or too high, one still needs treatment. We assert that the concept of internet sex addiction overstates dispositional factors and downplays external influence: a fundamental attribution error.

\section{References}

American Psychiatric Association (2010) APA Announces Draft Diagnostic Criteria for DSM-5 (News Release 4, 10 February). APA (http://www. eurekalert.org/pub_releases/2010-02/apa-aad020910.php).

DSM-5 Task Force (2012a) Hypersexual Disorder. American Psychiatric Association (http://www.dsm5.org/proposedrevision/pages/ proposedrevision. aspx?rid=415).

DSM-5 Task Force (2012b) R 37 Gambling Disorder. American Psychiatric Association (http://www.dsm5.org/proposedrevision/pages/ proposedrevision.aspx?rid=210).

Barth RJ, Kinder BN (1987) The mislabeling of sexual impulsivity. Journal of Sex \& Marital Therapy 13: 15-23.

BBC News Europe (2010) Spain 'busts child pornography network' (8 October). BBC (www.bbc.co.uk/news/world-europe-11503645).
Black DW, Kehrberg LL, Flumerfelt DL, et al (1997) Characteristics of 36 subjects reporting compulsive sexual behaviour. American Journal of Psychiatry 154: 243-9.

Bostwick JM, Bucci JA (2008) Internet sex addiction treated with naltrexone. Mayo Clinic Proceedings 83: 226-30.

Carnes P (1991) Sexual Addiction Screening Test (SAST). Tennessee Nurse 54 (3): 29

Carnes S, Carnes PJ (2010) Understanding cybersex in 2010. Family Therapy Magazine Jan/Feb 10-17.

Champion D (2010) On the Edge: BDSM and Heteronormative Denigration. Backlash (http://www.backlash-uk.org.uk/pdf/champion.pdf).

Cohen S (1972) Folk Devils and Moral Panics. St Martin's Press.

Cooper A, Scherer C, Boies S, et al (1999) Sexuality on the internet: from sexual exploration to pathological expression. Professional Psychology: Research and Practice 30: 154-64.

Cooper A, McLoughlin IP, Campbell KM (2000) Sexuality in cyberspace: update for the 21st century. CyberPsychology \& Behavior 3: 521-36.

Coopersmith $J$ (1999) The role of the pornography industry in the development of videotape and the Internet. In Proceedings of 1999 IEEE International Symposium on Women and Technology: Historical, Societal, and Professional Perspectives. Institute of Electrical and Electronics Engineers.

Criminal Law Policy Unit (2009) Possession of Extreme Pornographic Images and Increase in the Maximum Sentence for Offences under the Obscene Publications Act 1959: Implementation of Sections 63-67 and Section 71 of the Criminal Justice and Immigration Act 2008 (Circular No. 2009/01). Ministry of Justice (http://www.justice.gov.uk/publications/ docs/circular-criminal-justice-01-2009(1).pdf).

Delmonico D, Carnes P (1999) Virtual sex addiction: when cybersex becomes the drug of choice. CyberPsychology and Behavior 2: 457-63.

Divorce Wizards (2011) Divorce Statistics: Pornography. Cyberporn and Divorce. Divorce Wizards.

Durham M, Hughes D (1989) Thatcher halts survey on sex. Sunday Times, 10 September, p 61.

Dworkin A (1979) Pornography: Men Possessing Women. Perigee Books.

Garcia FD, Thibaut F (2010) Sexual addiction. American Journal of Drug and Alcohol Abuse 36: 254-60.

Garofalo R, Herrick A, Mustanski BS, et al (2007) Tip of the iceberg: young men who have sex with men, the internet, and HIV risk. American Journal of Public Health 97: 1113-7.

Goodman A (1990) Addiction: definition and implications. British Journal of Addiction 85: 1403-8.

Goodman A (2008) Neurobiology of addiction: an integrative review. Biochemical Pharmacology 75: 266-322.

Griffin-Shelley E (2003) The internet and sexuality: a literature review 1983-2002. Sexual and Relationship Therapy 18: 355-70.

Griffiths M (2000) Excessive internet use: implications for sexual behaviour. CyberPsychology \& Behavior 3: 537-52.

Hansard (2008) Criminal Justice and Immigration Bill debate. HL Deb, 21 April 2008, c1352. Hansard (http://www.publications.parliament. uk/pa/ld200708/ldhansrd/text/80421-0015.htm\#80421-0015.htm_ spnew12)

Henley J (2010) Are you addicted to sex? Guardian, 22 January (http:// www.guardian.co.uk/lifeandstyle/2010/jan/22/sex-addiction-tigerwoods-celebrities).

Herdt G (ed) (2009) Moral Panics, Sex Panics: Fear and the Fight Over Sexual Rights. New York University Press.

Kafka M (1997) Hypersexual desire in males: an operational definition and clinical implications for males with paraphilias and paraphilia-related disorders. Archives of Sexual Behaviour 26: 505-26.

Kalichman SC, Johnson JR, Adair V, et al (1994) Sexual sensation seeking: scale development and predicting AIDS-Risk behavior among homosexually active men. Journal of Personality Assessment 62: 385-97. 
Krueger RB, Kaplan MS, First MB (2009) Sexual and other axis I diagnoses of 60 males arrested for crimes against children involving the Internet. CNS Spectrums 14: 623-31.

Lajeunesse SL (2009) Université de Montréal professor refutes demonization of pornography (Press Release, 1 December). University of Montreal.

Lear E (1887) Edward Lear diaries: guide. Harvard University Library (http://oasis.lib.harvard.edu/oasis/deliver/ hou01884)

MacKinnon C (1984) Not a moral issue. Yale Law and Policy Review 2 : 321-45.

MacKinnon C (1987) Feminism Unmodified: Discourses on Life and Law. Harvard University Press.

Macnair T (2010) Sex addiction. BBC Health (http://www.bbc.co.uk/ health/emotional_health/addictions/sex_addiction.shtml).

Mars-Jones A (2001) Queerer and queerer: review of Edward Lear: The Complete Verse and Other Nonsense. Guardian, 11 November (www. guardian.co.uk/books/2001/nov/11/classics.highereducation).

Mitchell KJ, Becker-Blease KA, Finkelhor D (2005) Inventory of problematic internet experiences encountered in clinical practice. Professional Psychology: Research and Practice 36: 498-509.

Morgan R (1974) Going Too Far: The Personal Chronicle of a Feminist. Random House.

Moynihan R (2010) Merging of marketing and medical science: female sexual dysfunction. BMJ 341: c5050.

Murali V, George S (2007) Lost online: an overview of internet addiction. Advances in Psychiatric Treatment 13: 24-30.

Office of the United Nations High Commissioner for Human Rights (2000) Optional Protocol to the Convention on the Rights of the Child on the Sale of Children, Child Prostitution and Child Pornography. OHCHR (http:// www2.ohchr.org/english/law/crc-sale.htm).

Richters J, Grulich AE, de Visser R0, et al (2003) Sex in Australia: autoerotic, esoteric and other sexual practices engaged in by a representative sample of adults. Australia and New Zealand Journal of Public Health 27: 180-90.
Rubin G (1984) Thinking sex: notes for a radical theory of the politics of sexuality. In Pleasure and Danger: Exploring Female Sexuality (ed CS Vance). Routledge and Kegan Paul.

Serjeant J (2008) David Duchovny's sex disorder likened to alcoholism. Reuters (http://www.reuters.com/article/2008/08/29).

Smith J (2011) Jacqui Smith: my view of pornography. Independent, 1 March (http://http://www.independent.co.uk/life-style/love-sex/ jacqui-smith-my-view-of-pornography-2229430.html).

Wasko J (1994) Hollywood in the Information Age: Beyond the Silver Screen. Polity Press.

Watney S (1987) Policing Desire: Pornography, AIDS and the Media. University of Minnesota Press.

Weeks J (1981) The Making of the Modern Homosexual. Hutchinson.

Weeks J (1985) Sexuality and its Discontents. Routledge and Kegan Paul.

Weeks J (1986) Sexuality. Routledge.

Wellings K, Field J, Johnson AM, et al (1994) Sexual Behaviour in Britain: The National Survey of Sexual Attitudes and Lifestyles. Penguin Books.

Willis E (2005) Lust Horizons: the 'Voice' and the women's movement Village Voice, 18 October (http://www.villagevoice.com/2005-10-18/ specials/lust-horizons/l.

Winters J, Christoff K, Gorzalka BB (2010) Dysregulated sexuality and high sexual desire: distinct constructs? Archives of Sexual Behavior 39: 1029-43.

Wolak J, Mitchell K, Finkelhor D (2007) Unwanted and wanted exposure to online pornography in a national sample of youth internet users. Pediatrics 119: 247-57.

Yoder VC, Virden TB, Amin K (2005) Internet pornography and loneliness: an association? Sexual Addiction \& Compulsivity 12: 19-44.

Young KS, Griffin-Shelley E, Cooper A, et al (2000) Online infidelity: A new dimension in couple relationships with implications for evaluation and treatment. Sexual Addiction \& Compulsivity 7: 59-74.

\section{MCOs}

Select the single best option for each question stem

1 From estimates of web traffic on Alexa it can be inferred that:

a internet sex sites are the most popular sites visited on the net

b internet sex sites are ranked within the top ten most popular sites

c internet sex sites are free

$\mathrm{d}$ internet sex addiction is common

e the most popular internet sex site is ranked below 50 non-sex sites.

\section{Internet sex addiction}

a has been proven to be a growing menace

b involving men seeking sex with men is a marker of unsafe sexual practices

c has been invented by the therapy industry

$\mathrm{d}$ is a unitary behaviour

e does not exist as a concept.

\section{As regards moral panic as defined by} Cohen:

a the law against extreme pornography resulted from a moral panic

b the reaction to internet sex addiction is typical of a moral panic

c the response to HIV-positive men in the 1980s had all the elements of a moral panic

$\mathrm{d}$ there needs to be national consensus for a moral panic to be said to exist

e the term arose from Cohen's study of the gang culture of Hell's Angels.

4 In surveys of sexual behaviours:

a the Cooper study found that $92 \%$ of over 9000 individuals accessing sex sites reported no problems

b Kinsey studied a random sample of the general population

c the Welling study needed government funding to bail it out

$\mathrm{d}$ the Garofalo study of men who had sex with men contacted via the internet reported that a quarter inconsistently used condoms e the Richters telephone study of sex site users associated internet sex use with lower educational attainment.

\section{Associations with sex-related internet} use:

a in the Wolak study, a third of adolescents had been exposed to unwanted pornography in the past year

b Goodman proposed that bulimia, sex addiction, substance misuse and internet addiction share a common neurochemical basis

c the Krueger review of internet child offenders found that half had Axis I disorders

d the Black study of 36 self-declared sexually out-of-control men showed that about twothirds misused substances, a third had mood disorders and half had an anxiety disorder

e mental health workers seeing people with sexrelated internet problems report that sexual exploitation is the most common presentation. 